\title{
Multiple epiphyseal dysplasia, with severe proximal femoral dysplasia
}

INSERM

\section{Source}

INSERM. (1999). Orphanet: an online rare disease and orphan drug data base. Multiple epiphyseal dysplasia, with severe proximal femoral dysplasia. ORPHA:166029

Multiple epiphyseal dysplasia, with severe proximal femoral dysplasia is a rare primary bone dysplasia characterized by severe, early-onset dysplasia of the proximal femurs, with almost complete absence of the secondary ossification centers and abnormal development of the femoral necks (short and broad with irregular metaphyses). It is associated with gait abnormality, mild short stature, arthralgia, joint stiffness with limited mobility of the hips and irregular acetabula, and hip and knee pain. Coxa vara and mild spinal changes are also associated. 